\title{
Penggunaan Video Tutorial Gerak Dasar Senam untuk Meningkatkan Motorik Kasar Anak Tunagrahita Sedang
}

Tesi Ilhamri ${ }^{1}$, Marlina Marlina ${ }^{2}$

Pendidikan Luar Biasa, Fakultas Ilmu Pendidika, Universitas Negeri Padang, Indonesia ${ }^{1,2}$ E-mail: $\underline{\text { ilhamri.tesi@yahoo.co.id }{ }^{1} \text { marlina.muluk@gmail.com }{ }^{2}}$

\begin{abstract}
Abstrak
Bedasarkan permasalahan yang ditemukan di Sekolah Luar Biasa 02 Padang anak kesulitan dalam motorik kasar karena guru kurang memperhatikan anak saat melakukan kegiatan senam di sekolah. Penelitian ini bertujuan untuk meningkatkan motorik kasar anak tunagrahita sedang. Metode yang digunakan adalah metode eksperimen dengan pendekatan Single Subject Research, desain yang digunakan yaitu A-B-A. Teknik pengumpulan data dalam penelitian ini berupa observasi langsung dan tes. Subjek pada penelitian ini anak tunagrahita sedang kelas IV di SLBN 02 Padang. Hasil penelitian ini menunjukan kondisi kemampuan motorik kasar anak tunagrahita sedang menggunakan media video tutorial positif pada kemampuan motorik kasar anak.
\end{abstract}

Kata kunci: motorik kasar, video tutorial, tunagrahita sedang

\section{Abstract}

Based on the problems found in the SLBN 02 Padang children have difficulty in gross motor skills because teachers pay less attention to children when doing gymnastics activities at school. This study aims to improve the gross motor skills of mentally retarded children, the method research use is the experiment method with the Single Subject Research, and the design used is A-B-A. Data collection techniques in this study in the form of direct observation and test. The subject of this study was retarded children who were in class IV SLBN 02 Padang. The results of this study indicate that the condition of mentally retarded gross motor skills of children is using positive video tutorial media on the child gross motor skills.

Keywords: gross motoric, video tutorials, moderate impairment

Copyright (c) 2021 Tesi Ilhamri, Marlina Marlina

$\triangle$ Corresponding author

Address : komplek monang indah blok $\mathrm{f}$ no 2

Email : ilhamri.tesi@yahoo.co.id

ISSN 2580-3735 (Media Cetak)

Phone : 081371415107

ISSN 2580-1147 (Media Online)

DOI: https://doi.org/10.31004/basicedu.v5i1.594 


\section{PENDAHULUAN}

Masing-masing manusia di dalam kehidupan membutuhkan pendidikan karena tidak adanya pendidikan kita tidak bisa ke depan dalam memecahkan suatu masalah, pendidikan merupakan keinginan dalam mendapatkan ilmu pengetahuan, sangat bermafaat didalam kehidupan (Asyhar, 2011) diri sendiri serta di dalam lingkungan masyarakat. Setiap individu-individu berharap memperoleh pendidikan begitu pun anak berkebutuhan khusus juga memerlukan pelayanan khusus dalam pendidikannya sesuai dengan hambatan yang dialaminya yang disebut dengan pendidikan anak berkebutuhan khusus (Marlina \& Kusumastuti, 2019).

Pendidikan anak berkebutuhan khusus di dalamnya terdapat anak yang mengalami keterbelakangan mental sehingga anak memerlukan pelayanan khusus tujuannya sama dengan pendidikan anak normal lainnya. Pendidikan anak berkebutuhan khusus sangat penting bagi kelangsungan hidupnya dan anak dapat berinteraksi dengan orang lain serta di dalam pendidikannya harus sesuai dengan jenis, karateristik anak tersebut. Anak berkebutuhan khusus diantaranya seperti anak tunagarahita sedang yang mengalami gangguan pada motorik kasarnya (Rizal, Fatmawati, \& Martias, 2013).

Motorik kasar ialah suatu kemampuan gerak pada anak tunagrahita sedang yang melibatkan otot-otot kasar pada tangan dan kaki serta melibatkan anggota tubuh yang lain seperti mata, contohnya gerak yang melibatkan anggota tubuh tangan, kaki dan mata adalah mendorong, melempar, menangkat dan mengangkat, motorik kasar ini terdapat gerak yang terdiri dari gerakan lokomotor, non loomotor sehinnga motorik kasar ini sangat penting untuk dikembangkan (Rela, Wati \& Widajati, 2018).
Motorik kasar anak tunagarahita sedang ini sangat penting untuk dikembangkan terutama yang berkaitan dengan aspek kelenturan, keseimbangan, daya tahan dan koordinasi antar anggota tubuh siswa tersebut didalam melakukan aktivitas seharihari di kehidupan yang mereka jalani dengan mandiri. Agar dapat membantu dirinya sendiri, gerakan motorik kasar siswa yang baik akan melatih otot-otot yang ada didalam tubuh untuk menjadi lebih maksimal lagi (Wati, 2016).

Supaya maksmial perkembangan kemampuan motorik siswa tunagrahita salah satunya dapat dilakukan melalui pembelajaran gerak dasar, aktivitas gerak dalam keterampilan olah tubuh siswa yang mudah ditiru bisa dilakukan belajar sambil bermain serta bisa dilakukan kapan saja dan dimana saja seperti gerak dasar senam (Ratnayanti \& Kustiawan, 2014). Gerak dasar senam ialah suatu gerakan yang membutuhkan kekuatan kecepatan dan keserasian gerak fisik yang teratur gerak dasar senam sangat penting untuk pembentukan kelenturan tubuh, kelenturan tubuh sering diartikan sebagai kemampuan seseorang untuk menggerakkan tubuh atau bagianbagian dalam satu ruang gerak yang seluas-luas mungkin, tanpa mengalami cedera pada persendian dan otot sekitar persendian (Rismayanthi, 2013).

Berdasarkan studi pendahuluan yang peneliti lalukan pada saat melaksanakan PL, peneliti mengamati satu orang siswa tunagrahita kelas IV yang berinisial DA dimana dalam proses belajar olahraga siswa terlihat malas dan sering keluar meminta izin sehingga pada saat dilakukan asesmen peneliti menemukan bahwa siswa berinisial DA mengalami hambatan dalam pembelajaran DA kesulitan dalam menyerap pembelajaran, terlebih dalam pembelajaran olahraga yang mana biasanya pembelajaran olahraga adalah pembelajaran yang berupa olah 
tubuh seperti gerakan pada tubuh. Berdasarkan penilaian yang peneliti lakukan peneliti mendapatkan bahwa siswa dalam berdiri dengan satu kaki siswa tidak bisa serta menunjukkan gerakan berdiri dengan satu kaki siswa juga tidak bisa, jalan ditempat siswa juga kaku serta di dalam senam siswa malas berdiri saja melihat temannya, anak juga tidak ikut dalam pelaksanan senam.

Di sekolah guru kurang memperhatikan motorik kasar anak guru hanya menerangan pelajaran, merajuk pada permasalahan tersebut, peneliti memilih suatu media yang dianggap cocok dengan kebutuhan anak tunagrahita sedang yaitu menggunakan video tutorial, video tutorial ialah suatu rangkaian gambar hidup yang ditayangkan oleh seorang pengajar yang berisi pesan-pesan pembelajaran untuk membantu pemahaman terhadap suatu materi pembelajaran untuk peserta didik (Velina, 2014) karena video tutorial bisa menarik perhatian orang yang melihatnya serta menggambarkan suatu proses secara tepat yang dapat disajikan secara berulang-ulangjuga cocok digunakan pada pembelajaran yang bersifat pratek (Chandra \& Nugroho, 2016) dan media video tutorial dianggap lebih baik dan menarik dari media lain yaitu dengan melihat video tutorial anak dapat melihat gerakan sambil mendengar (Hendri \& Damri, 2019).

\section{METODE}

Jenis penelitian yang digunakan dalam penelitian ini yaitu eksperimen dalam bentuk penelitian subjek tunggal atau disebut juga dengan Single Subject Research (SSR). Pada penelitian ini desain yang digunakan yaitu A-B-A. Baseline (A1) merupakan kondisi dimana subjeck belum mendapat perlakuan yang diamati secara alami sebanyak tiga atau sampai lima trend dan level data stabil. Kondisi intervensi merupakan kondisi apabila suatu intervensi telah diberikan kemudian perilaku sasaran diukur dibawah kondisi tersebut. Adapun tujuan dari kondisi intervensi ini yaitu melihat tingkahlaku yang terjadi selagi diberikannya perlakuan. Intervensi yang diberikan yaitu media video tutorial. Baseline (A2) merupakan melakukan pengamatan kembali sebagai evaluasi ada atau tidaknya pengaruh perlakuan yang diberikan terhadap motorik kasar anak tunagrahita (Arikunto, 2005).

Penelitian ini dilakukan di SLB 2 Padang dengan subjek penelitian anak tunagrahita sedang kelas IV anak terlihat kaku dalam melakukan gerakan olahraga serta dijam pelajaran anak berdiri saja. Dalam penelitian ini target behavior-nya yaitu motorik kasar. Teknik pengumpulan data penelitian ini menggunakan instrumen tes, sebagai alat ukur instrumen tersebut dibuat berdasarkan item pada gerak dasar senam dalam motorik kasar anak yang dilakukan saat anak pulang sekolah kemudian data dianalisis dengan analisis visual grafik dan dianalisis setiap fase.

\section{HASIL DAN PEMBAHASAN}

\section{Analisis Dalam Kondisi}

Penelitian ini dilakukan sebanyak 17 kali pertemuan pada satu orang siswa. Penelitian ini dilakukan dalam tiga kondisi untuk melihat kemampuan motorik kasar aanak tunagrahita sedang. Kondisi pertama ialah basaline (A1), pada kondisi ini peneliti mengamata bagaimana motorik kasar anak sebelum melakukan intervensi menggunakan video tutorial gerak dasar senam. Selanjutnya kondisi kedua yaitu intervensi (B) pada kondisi ini peneliti mengamati bagaimana motorik kasar anak ketika diberikan intervensi menggunakan media video tutorial gerak dasar senam. Kondisi keiga ialah baseline (A2) pada tahap ini peneliti mengamati bagaimana motorik 
kasar anak setelah diberikan intervensi. Ketiga baseline pada penelitian ini bisa dilihat pada grafik dibawah ini :

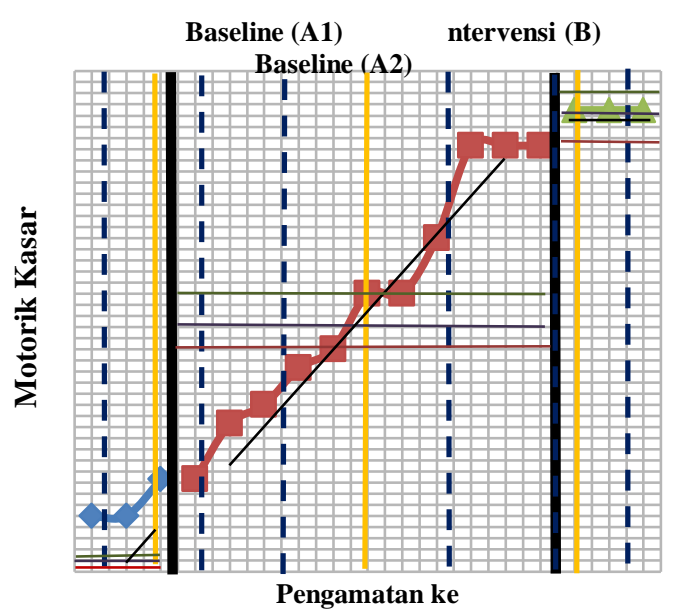

Grafik 1 Analisis dalam Kondisi Data Motorik Kasar

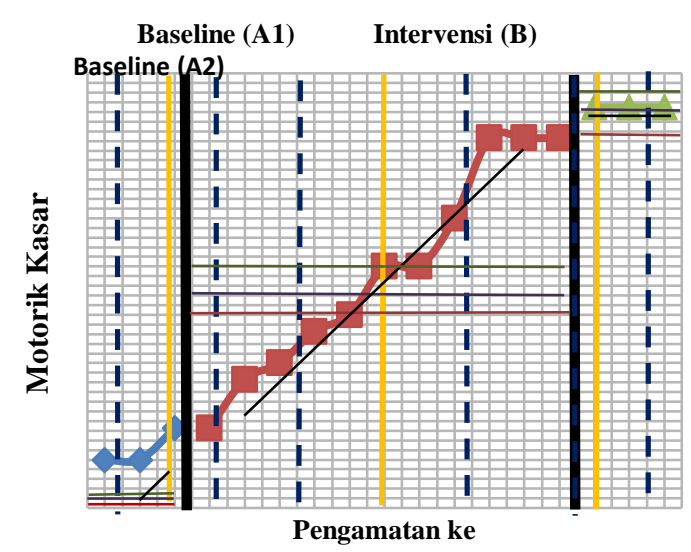

Grafik 2 Analisis Antar Kondisi Data Motorik Kasar

Keterangan :

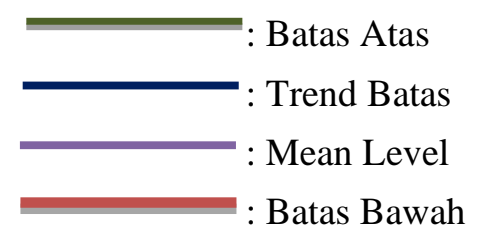

\section{Kondisi Siswa DF}

Pada kondisi (A1), pengamatan dilakukan sebanyak tiga kali pertemuan, pada hari pertama siswa tidak mampu melaksanakan dari lima belas butir instrumen. Untuk hari kedua siswa juga tidak mampu melakukan dari lima belas butir instrumen, sedangkan pada pertemuan ketiga siswa mengalami peningkatan yaitu mampu satu dengan bantuan dari lima belas butir instrumen. Peneliti melanjutkan pada kondisi intervensi.

Pengamatan pada kondisi intervensi (B) dilaksanakan sebanyak sebelas kali pertemuan. Pada pengamatan di hari pertama, siswa bisa melaksakan satu dengan bantuan dari butir instrumen yang ada, untuk pengamatan pada hari kedua siswa mengalami peningkatan dengan hari sebelumnya dari lima belas butir instrumen yang ada, pada pengamatan ketiga siswa mengalami satu peningkatan dengan melakukan tiga dari lima belas butir instrumen. Setiap hari siswa mengalami peningkatan sampai pertemuan hari kedelapan siswa sudah mampu melakukan tujuh dari lima belas butir instrumen, pada pertemuan kesembilan siswa mampu melakukan sepuluh dari lima belas butir istrumen yang ada berhubungan dengan kemampuan siswa pada dua kondisi telah stabil, maka peneliti melanjutkan pada kondisi berikutnya, ialah pada tahap baseline akhir (A2). Pada kondisi ini, kemampuan siswa bisa melakukan sebelas dari lima belas butir instrumen yang ada kempuan siswa tetap stabil pada dua kali pertemuan berikutnya dengan lima belas butir instrumen walau pun tidak lagi diberikan intervensi.

Dilanjutkan dengan melakukan analisis data, berdasarkan analisis tersebut diperoleh data sebagai berikut: pada baseline (A1) menunjukan kecenderungan arah yang meningkat $(+)$. Persentase stabilitas pada kondisi (A1) adalah 15\% dengan batas atas $2,7 \%$, batas bawah sebesar $1,7 \%$ 
dan mean level 2,2\%. Pada tahap intervensi (B) menunjukan persentase stabilitas $10 \%$ dengan batas atas $44,6 \%$ batas bawah $34,6 \%$ dan meal level 39,6\%. Pada tahap baseline (B) setelah diberikan intervensi mean level sebesar $73 \%$ dengan batas atas 78,5 dan batas bawah $67,5 \%$.

Data terakhir pada kondisi (A1) ialah 6,6\% data pertama pada kondisi (B) ialah 6,6\%. Dapat ditentukan level perubahan dengan cara mengurangi pada data terakhir pada kondisi (A1) data pertama pada intervensi, sehingga diperoleh selisihnya keduanya ialah 0 . Sedangkan data terakhir pada kondisi (B) adalah 66,6 dan data pertama pada kondisi (A2) ialah 73 dapat ditentukan level perubahan dengan cara mengurangi data pertama pada kondisi (A2) dengan data pertama pada kondisi intervensi. Sehingga diperoleh selisih pada kedua data tersebut ialah 1. Bisa diketahui bahwa adanya kestabilan pada level perubahan. Untuk persentase overlap pada kondisi awal intervensi adalah 0\%, sedangkan pada kondisi intervensi dan kondisi akhir ialah 9,09\%.

\section{Pembahasan}

Dalam penelitian ini peneliti meningkat motorik kasar anak tunagrahita sedang yaitu dengan gerak dasar senam menggunakan video tutorial penelitian ini membutuhkan video tutorial gerak dasar senam agar bisa melakukan mengajarkan motorik kasar untuk anak tunagrahita sedang. Hal yang terpenting dalam video tutorial gerak dasar senam disana harus ada gerakan yang akan diajarkan dan mudah dipahami pada anak (PUSPITASARI PANDONGAN, 2014).

Pengamatan dilakukan dengan tiga kondisi yaitu kondisi baseline (A1) sebelum mendapatkan perlakuan dengan mengamati motorik kasar anak, intervensi (B) setelah diberikan media video tutorial gerak dasar senam dan baseline (A2) mengamati kembali motorik kasar anak tunagrahita sedang melalui media video tutorial gerak dasar senam yang telah diajarkan sambil bermain.

Respon anak yang begitu rendah disebabkan kurangnya perhatian dari guru dan orang tua dan perilaku anak sering diam serta mengabaikan orang yang ada disekitarnya serta kebiasaan anak yang suka menghabiskan waktu sendiri kalau disuruh siswa hanya berdiri dengan diam saja. Siswa dengan berkebutuhan khusus cendrung mengalami kesulitan dalam partisipasi sosial, mereka memiliki lebih sedikit teman, mereka juga lebih banyak berinteraksi dengan guru mereka dan kurang diterima oleh teman sebaya yang normal di sekolah inklusi (Marlina \& Kusumastuti, 2019) Penelitian ini relevan dengan penelitian sebelumnya (Amda \& Marlina, 2019) yang menyatakan bahwa melalui media video tutorial dapat meningkatkan keterampilan desain grafis dalam menyelesaikan setiap langkah-langkah pembuatan siluet wajah dengan benar, selain gerak dasar senam tarian jarangan bisa meningkatkan motorik kasar anak sesuai dengan penelitian (Wahyuningsih, 2014).

Berdasarkan analisis data yang telah dilakukan dapat dijelaskan bahwa setelah diberikan perlakuan berupa media video tutorial gerak dasar senam kemampuan dalam motorik kasar anak tunagrahita sedang mengalami peningkatan, sehingga media video tutorial berpengaruh dalam meningkatan keterampilan motorik kasar anak tuangrahita sedang di SLBN 02 Padang.

\section{SIMPULAN}

Dari hasil penelitian yang telah dilakukan, dapat disimpulkan bahwa kemampuan motorik kasar melalui media pembelajaran video tutorial gerak dasar senam pada siswa tunagrahita kelas IV 
di SLB Negeri 2 Padang mengalami peningkatan dari kemampuan awal yang dimiliki siswa. Dari keseluruhan menunjukkan adanya perubahan kemampuan motorik kasar pada anak tunagrahita sedang meningkat kearah yang lebih baik. Hasil perolehan data ini menunjukkan bahwa model pembelajaran video tutorial dapat digunakan dalam meningkatkan kemampuan menulis kalimat pada anak tunagrahita.

\section{DAFTAR PUSTAKA}

Amda, N. R., \& Marlina, M. (2019). EFEKTIVITAS VIDEO TUTORIAL UNTUK MENINGKATKAN KETERAMPILAN DESAIN GRAFIS BAGI ANAK TUNARUNGU. Ranah Research: Journal of Multidisciplinary Research and Development, 2(1), 1-6.

Arikunto, S. (2005). Management Penelitian. Jakarta: Rineka Cipta.

Asyhar, R. (2011). Kreatif Mengembangkan Media Pembelajaran. Jakarta: Gaung Persada Press.

Chandra, F. H., \& Nugroho, Y. W. (2016). Peran teknologi video dalam flipped classroom. Jurnal Dinamika Teknologi, 8(1), 15-20.

Hendri, S. K., \& Damri, D. (2019). Peningkatan Kemampuan Bina Diri Melalui Media Audio Visual pada Anak Tunagrahita Ringan. Jurnal Pendidikan Kebutuhan Khusus, 3(1), 12-17.

Marlina, M., \& Kusumastuti, G. (2019a). Social Participation of Students with Special Educational Needs in Inclusive Elementary Schools/Specialiujų Ugdymosi Poreikių Turinčių Mokinių Socialinis Dalyvavimas Inkliuzinèje Pradinio Ugdymo Mokykloje. Specialusis Ugdymas/Special Education, 1(39), 109-132.

Marlina, M., \& Kusumastuti, G. (2019b). Social participation of students with special eucational needs in inclusive elementary schools. Specialusis Ugdymas/Special Education, 1(39), 121-131.

PUSPITASARI PANDONGAN, E. K. A. (2014). TARI JARANAN MODIFIKASI

\author{
BERMEDIA VCD TERHADAP \\ KEMAMPUAN MOTORIK KASAR ANAK \\ TUNAGRAHITA RINGAN. Jurnal \\ Pendidikan Khusus, 5(2).
}

Ratnayanti, R., \& Kustiawan, U. (2014). Pengaruh Penerapan Pembelajaran Tari Kreasi Terhadap Kemampuan Motorik Kasar Siswa Tunagrahita di Sekolah Dasar Luar Biasa. Jurnal Ortopedagogia, 1(3), 238-244.

Rela, Wati, E., \& Widajati, W. (2018). TARI MERAK MODIFIKASI TERHADAP KEMAMPUAN MOTORIK Diajukan kepada Universitas Negeri Surabaya Abstract :, 1-16.

Rismayanthi, C. (2013). Mengembangkan Keterampilan Gerak Dasar Sebagai Stimulasi Motorik Bagi Anak Taman Kanak-kanak Melalui Aktivitas Jasmani, 9(April).

Rizal, R. J., Fatmawati, F., \& Martias, Z. (2013). Mengatasi Substitusi Menulis Permulaan melalui Metode VAKT bagi Anak Tunagrahita Ringan Kelas IV di SDLB Negeri 20 kota Pariaman (Single Subject Research Kelas IV di SDLB Negeri 20 kota Pariaman). Jurnal Penelitian Pendidikan Khusus, 2(2).

Velina, R. (2014). Efektivitas Media Video Tutorial dalam Meningkatkan Kemampuan Membuat Kreasi Stoples bagi Siswa Tunagrahita Ringan, 3(April), 1-16.

Wahyuningsih, A. (2014). Pengaruh Tari Jaranan Modifikasi Bermedia VCD Terhadap Kemampuan Motorik Kasar Anak Tunagrahita Ringan. Jurnal Pendidikan Khusus, 1(1), 1-8. https://doi.org/10.1109/EDUCON.2011.5773 297

Wati, L. (2016). Pengaruh Model dan Media Pembelajaran Terhadap Hasil Belajar Kemampuan Dasar Senam pada Mahasiswa, 5(1), 97-112. 